03,13

\title{
Эффективное фотопреобразование в гетероструктуре на основе оксида меди (I) и оксида кадмия-олова
}

\author{
(C) Г.Н. Шелованова, Т.Н. Патрушева \\ Сибирский федеральный университет, \\ Красноярск, Россия \\ ฯ E-mail: pat55@mail.ru \\ (Поступила в Редакцию 29 июня 2016 г.)
}

Для создания солнечного элемента предложена гетероструктура, состоящая из анодного оксида меди $\mathrm{Cu}_{2} \mathrm{O}$ на медной подложке и прозрачной проводящей пленки $\mathrm{Cd}-\mathrm{Sn}-\mathrm{O}$. Авторы данной работы ориентировались на простоту и доступность методов получения пленок и остановили свое внимание на методе анодного окисления для формирования оксида $\mathrm{Cu}_{2} \mathrm{O}$ и экстракционно - пиролитического метода для получения прозрачного проводящего слоя $\mathrm{Cd}-\mathrm{Sn}-\mathrm{O}$. Показана возможность значительного повышения эффективности фотопреобразования в структуре $\mathrm{Cu}-\mathrm{Cu}_{2} \mathrm{O} / \mathrm{Cd}-\mathrm{Sn}-\mathrm{O}$ по сравнению со структурой $\mathrm{Cu}-\mathrm{Cu}_{2} \mathrm{O}$.

Работа выполнена при поддержке КФН-РФФИ грант № 15-48-04224.

DOI: 10.21883/FTT.2017.02.44041.250

\section{1. Введение}

Необходимость решения энергетических проблем, связанных с истощением традиционных источников энергии и ухудшением экологического состояния Земли, привлекает внимание к разработке устройств прямого преобразования энергии солнечного излучения в электричество. Одним из ключевых моментов является поиск новых материалов и структур для эффективного фотопреобразования. К таким перспективным материалам относится, в частности, оксид меди (I), свойства которого исследуются с 20-х годов прошлого столетия. Тогда были созданы меднозакисные выпрямители, изучались их фотоэлектрические свойства.

На время интерес к $\mathrm{Cu}_{2} \mathrm{O}$ уменьшился из-за появления новых полупроводниковых соединений, однако он вновь возрос в связи с современными технологическими возможностями.

Для подавляющего большинства солнечных элементов основой служит $p-n$-переход, для получения которого нельзя обойтись без высокотемпературных и энергозатратных процессов. В случае $\mathrm{Cu}_{2} \mathrm{O}$ подобных решений не требуется. Типовые полупроводниковые солнечные элементы чувствительны к повышению температуры, изза чего снижается эффективность использования фокусирующих систем, так как при перегреве полупроводника снижается КПД фотопреобразования. По сравнению с кремнием оксид меди (I) из-за большей ширины запрещенной зоны может выдерживать более высокие температуры перегрева. Помимо низкого сопротивления медь, используемая в качестве подложки, обладает еще и высочайшей теплопроводностью, хорошо рассеивает тепло. Это позволяет использовать фокусирующие системы без дополнительных систем охлаждения, что также снижает стоимость получения солнечной батареи из данных элементов.
Для создания солнечного элемента необходим второй электрический контакт, роль которого выполняет прозрачная проводящая пленка $\mathrm{Cd}-\mathrm{Sn}-\mathrm{O}$, нанесенная на поверхность $\mathrm{Cu}_{2} \mathrm{O}$. Для увеличения проводимости пленок без потери прозрачности в литературе предложены составы двойных и тройных оксидов [1]. Интерес представляют пленки из растворов экстрактов кадмия и олова. При этом электрические свойства оксидов кадмия, легированных оловом или цинком, превосходят показатели других прозрачных проводящих пленок.

\section{2. Материалы и методы}

К перспективным способам получения $\mathrm{Cu}_{2} \mathrm{O}$ относятся термическое окисление, электроосаждение, химическое осаждение, анодное окисление.

Авторами данной работы оксид одновалентной меди был получен методом анодного окисления электротехнической медной фольги марки М0 (99.95\% меди) в электрохимической ячейке с платиновым катодом. Перед анодированием поверхность фольги механически очищали от оксидов, обезжиривали в горячем содовом растворе, а затем проводили электрохимическую полировку в водном растворе сульфаминовой кислоты при плотности тока $j=100 \mathrm{~mA} / \mathrm{cm}^{2}$ в течение $3 \mathrm{~min}$ для дополнительной очистки поверхности.

Проводящие пленки с высокой прозрачностью получают дорогостоящими методами магнетронного напыления или электронно-лучевого нанесения, требующими использования вакуумного оборудования, высокочистых химических реактивов и значительных затрат энергии. Однако, поскольку соединения кадмия являются токсичными, их получение традиционными методами вакуумного распыления мишеней не получило распространения. Нами для получения сложнооксидных пленок использован экстракционно-пиролитический метод [2], 
который и был применен в данной работе с целью формирования пленки $\mathrm{Cd}-\mathrm{Sn}-\mathrm{O}$. Метод заключается в экстракционном извлечении целевых компонентов из водных растворов, смешивании экстрактов в требуемом соотношении, нанесении на подложки смеси экстрактов и пиролизе. Выбор данного метода обусловлен гомогенностью (однородностью) промежуточных и конечных продуктов, получением материалов с любым соотношением целевых компонентов. В качестве экстрагента использована смесь карбоновых кислот (капроновая, каприловая, энантовая и пеларгоновая). Методом экстракции получены карбоксилаты кадмия и олова. Для уточнения концентрации металлов в экстрактах были получены реэкстракты, которые исследованы методом атомной абсорбции на приборе AAS-3 для уточнения концентрации металла. Рабочие растворы были приготовлены смешиванием экстрактов в заданном соотношении $1: 1,2: 1,4: 1,6: 1,8: 1$. Приготовленные растворы использовались для нанесения пленок $\mathrm{Cd}-\mathrm{Sn}-\mathrm{O}$ заданного состава методом вращения подложки.

Растворы солей карбоновых кислот обладают низким поверхностным натяжением и хорошо смачивают любые подложки. Для равномерного распределения раствора по поверхности подложки использован метод центрифугирования в течение $1 \mathrm{~min}$ при скорости вращения центрифуги 2500-3000 rpm. Подсушенный при комнатной температуре слой помещали в вертикальную печь для пиролиза при температуре $450^{\circ}$ на $3 \mathrm{~min}$. После охлаждения пленки циклы нанесения раствора, подсушивания и пиролиза повторялись 3-5 раз до достижения толщины пленки 50-150 nm. Толщина пленок оценивалась по расклинивающему давлению раствора, рассчитанному на основании данных о поверхностном натяжении [3].

Для методов анодного окисления и экстракционнопиролитического практически нет ограничений по площади получаемых структур.

Полученные образцы были исследованы физикохимическими методами. Рентгенофазовый анализ пленки $\mathrm{Cu}_{2} \mathrm{O}$ выполнен на дериватографе ДРОН-3. Микроструктура пленки закиси меди исследовалась на растровом электронном микроскопе (РЭМ) Hitachi TM-1000. Дифрактограммы получены с использованием $\mathrm{Cu} K \alpha$ излучения на дифрактометре X'Pert PRO с детектором PIXcel (PANalytical).

Тип проводимости $\mathrm{Cu}_{2} \mathrm{O}$ определяли методом термоэдс [4]. В данной работе с целью определения ширины запрещенной зоны $\mathrm{Cu}_{2} \mathrm{O}$ исследовали зависимость сопротивления полупроводника от температуры. Образец помещался в измерительную камеру с электронагревателем. Сопротивление регистрировалось цифровым прибором. Температура измерялась дифференциальной термопарой, на ее свободных концах образуется термоэдс, которая пропорциональна разности комнатной и измеряемой температур. Значения термоэдс фиксировались цифровым вольтметром. Температуру определяли по специальной градуировочной таблице на основе значений термоэдс.

\section{3. Формирование слоя $\mathrm{Cu}_{2} \mathrm{O}$ на медной подложке и свойства структуры $\mathrm{Cu} / \mathrm{Cu}_{2} \mathrm{O}$}

При получении анодной закиси меди обычно применяют электролиты на основе серной кислоты и гидроксида калия, при этом наряду с оксидом $\mathrm{Cu}_{2} \mathrm{O}$ формируется побочный $\mathrm{CuO}$, который не столь фотоактивен, как оксид одновалентной меди. В качестве электролита нами использован 5\%-й водный раствор сульфаминовой (амидосерной) кислоты $\mathrm{NH}_{2} \mathrm{SO}_{3} \mathrm{H}$. При температуре $20-30^{\circ} \mathrm{C}$ максимальная концентрация сульфаминовой кислоты в водном растворе составляет $10 \%$, однако при этой концентрации образовавшийся оксид тут же и стравливается. Понижая последовательно концентрацию, авторы получили устойчивое формирование $\mathrm{Cu}_{2} \mathrm{O}$ в $5 \%$-м растворе $\mathrm{NH}_{2} \mathrm{SO}_{3} \mathrm{H}$.

$\mathrm{C}$ увеличением времени анодного процесса толщина пленки растет при всех принятых значениях плотности тока. Однако рост плотности тока приводит к увеличению приложенного напряжения, в результате чего про-

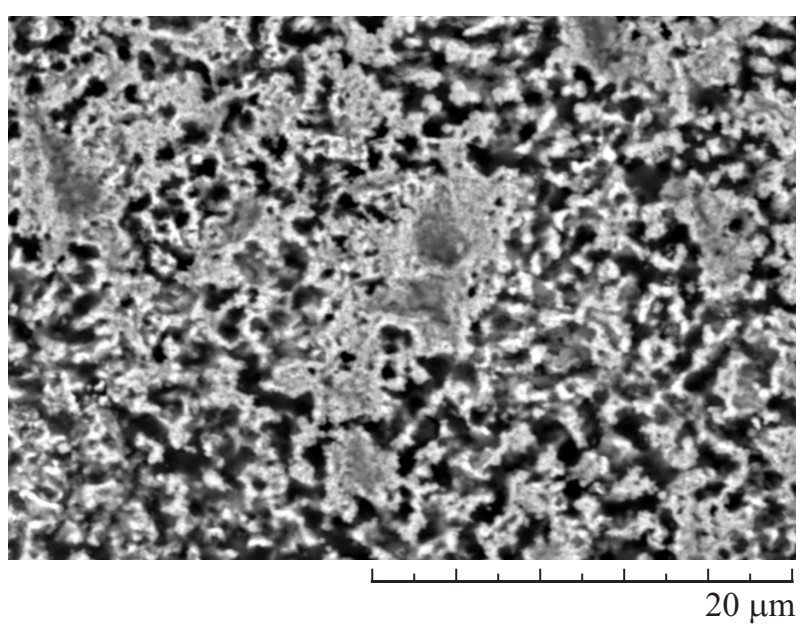

Рис. 1. Микрофотография пленки $\mathrm{CuO}_{2}$.

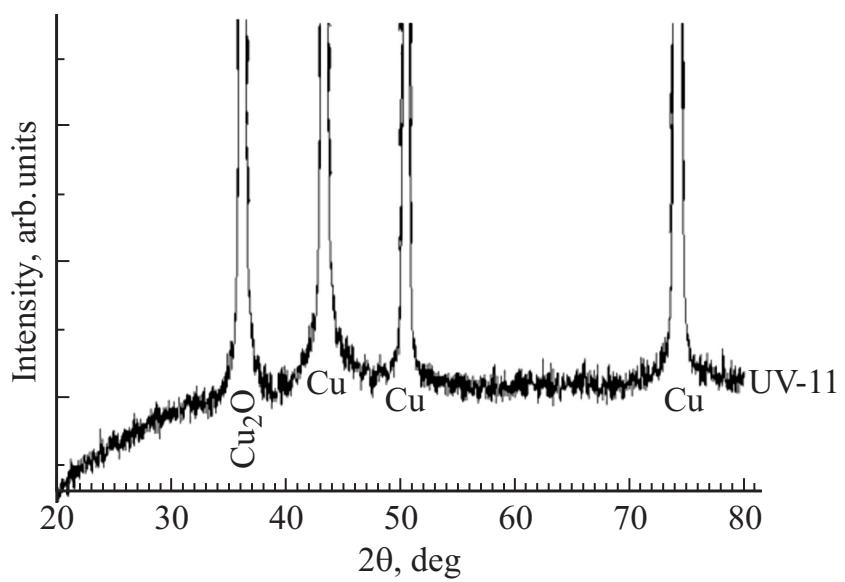

Рис. 2. Рентгенограмма образца пленки $\mathrm{Cu}_{2} \mathrm{O}$ на медной подложке. 


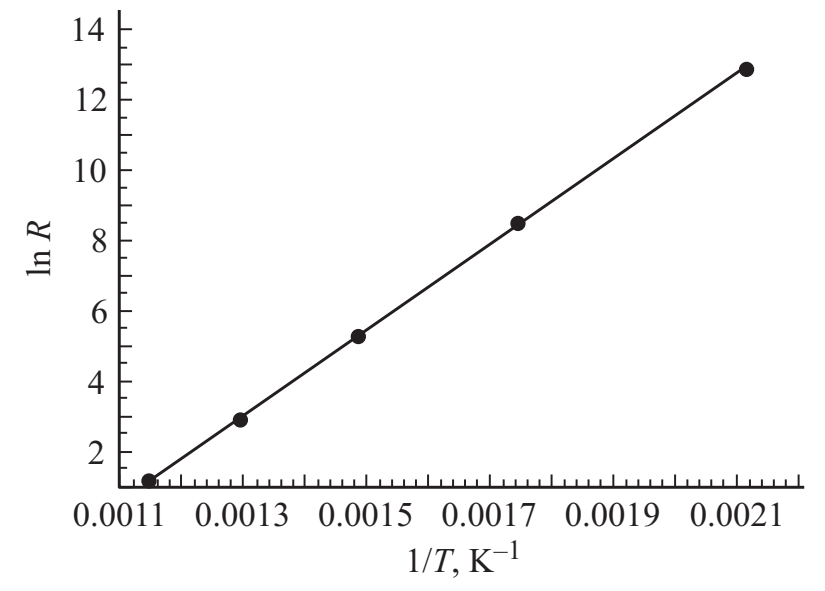

Pис. 3. Зависимость логарифма сопротивления пленки $\mathrm{Cu}_{2} \mathrm{O}$ от обратной температуры.

исходит подтравливание пленки из-за включения механизма полировки, что приводит к уменьшению толщины пленки. Так, при плотности тока анодирования $2 \mathrm{~mA} / \mathrm{cm}^{2}$ максимальная толщина пленок составила $6 \pm 0.5 \mu \mathrm{m}$, в то время как при $6 \mathrm{~mA} / \mathrm{cm}^{2}-$ порядка $3 \pm 0.5 \mu \mathrm{m}$.

Визуально образование в пленке $\mathrm{Cu}_{2} \mathrm{O}$ обнаружено при воздействии водным раствором аммиака: в нем $\mathrm{Cu}_{2} \mathrm{O}$ растворяется, образуя бесцветный комплекс $\left[\mathrm{Cu}\left(\mathrm{NH}_{3}\right)_{2}\right]^{+}$, который на воздухе быстро окисляется до $\left[\mathrm{Cu}\left(\mathrm{NH}_{3}\right)_{4}\left(\mathrm{H}_{2} \mathrm{O}\right)_{2}\right]_{2}^{+}$синего цвета.

На рис. 1 приведено РЭМ-изображение пленки анодного $\mathrm{Cu}_{2} \mathrm{O}$. Видна разветвленная структура, которая позволяет увеличить площадь воздействия фотонов, что повышает эффективность фотопреобразования.

Рентгенограмма (рис. 2) свидетельствует об отсутствии в пленке побочных продуктов электрохимической реакции, что говорит о корректности выбора электролита и режимов формирования $\mathrm{Cu}_{2} \mathrm{O}$.

Все пленки оказались с проводимостью $p$-типа, что находится в согласии с приводимыми в литературе данными для этого материала, полученного анодным окислением [5]. Известно, что ширина запрещенной зоны анодного оксида меди составляет $1.8-2.2 \mathrm{eV}$ в зависимости от способа его получения. Так, например, согласно публикациям закись меди, полученная термическим окислением, имеет ширину запрещенной зоны $1.9 \mathrm{eV}$, для случая получения этого соединения низкотемпературным химическим осаждением сообщается о ширине запрещенной зоны $2.36 \mathrm{eV}$, а при анодном окислении меди в растворах серной кислоты ширина запрещенной зоны составляет $2.2 \mathrm{eV}$ [6-9].

Как и всякий полупроводник, оксид меди (I) обнаружил с повышением температуры экспоненциальное уменьшение сопротивления вследствие тепловой генерации носителей заряда (рис. 3).

Значение ширины запрещенной зоны рассчитали из зависимости сопротивления от температуры

$$
E_{g}=2 k \operatorname{tg} \alpha=2 k \frac{\ln R_{1}-\ln R_{2}}{\frac{1}{T_{1}}-\frac{1}{T_{2}}},
$$

где $E_{g}$ - ширина запрещенной зоны, $k-$ постоянная Больцмана, $R_{1}, R_{2}$ - значения сопротивления соседних точек, $T_{1}, T_{2}$ - температуры этих точек.

Значение ширины запрещенной зоны составило $2.13 \mathrm{eV}$.

Дополнительным подтверждением этого результата является спектрограмма, полученная на спектрофотометре Specord M400 (рис. 4). На спектрограмме изменение оптической плотности происходит на длине волны $580 \mathrm{~nm}$, что соответствует значению ширины

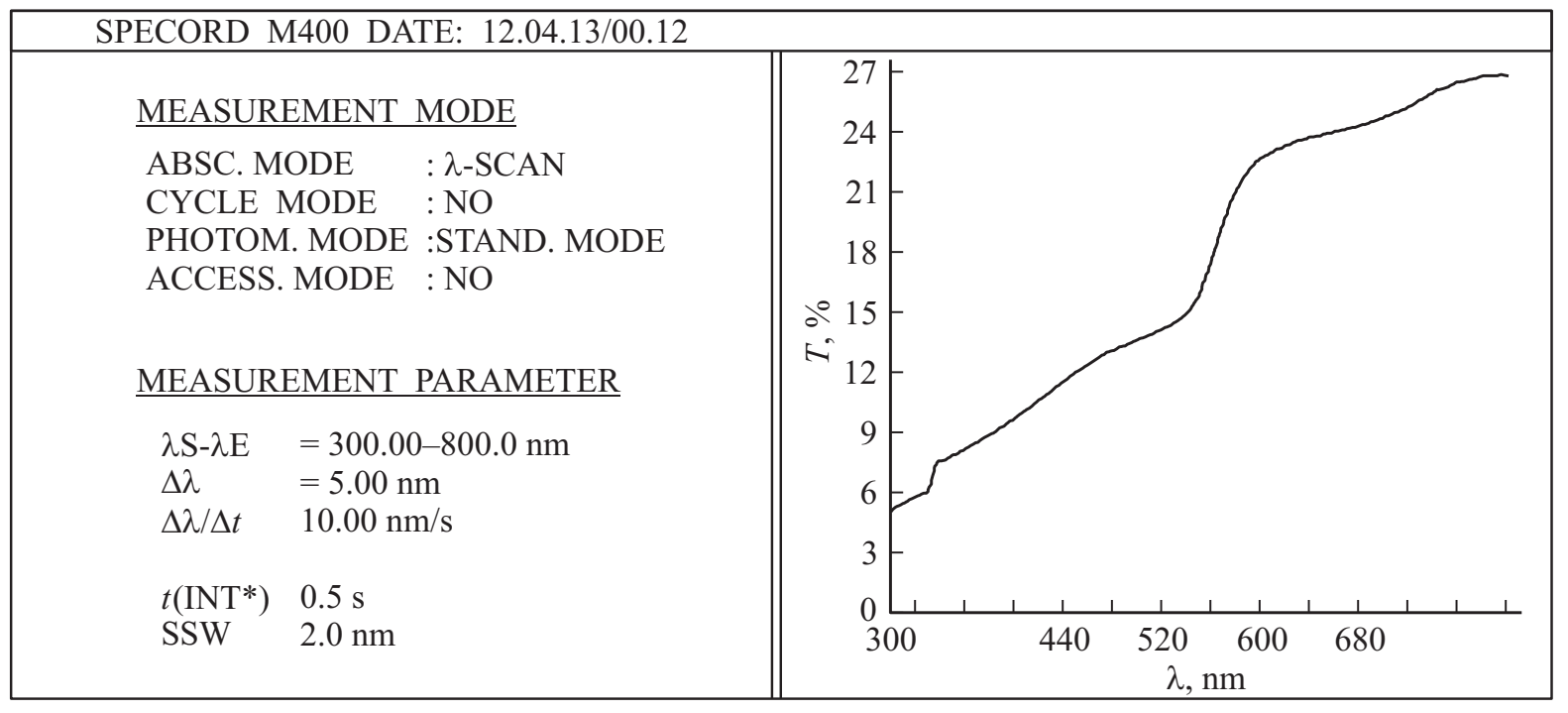

Pис. 4. Спектр отражения анодного $\mathrm{Cu}_{2} \mathrm{O}$. 


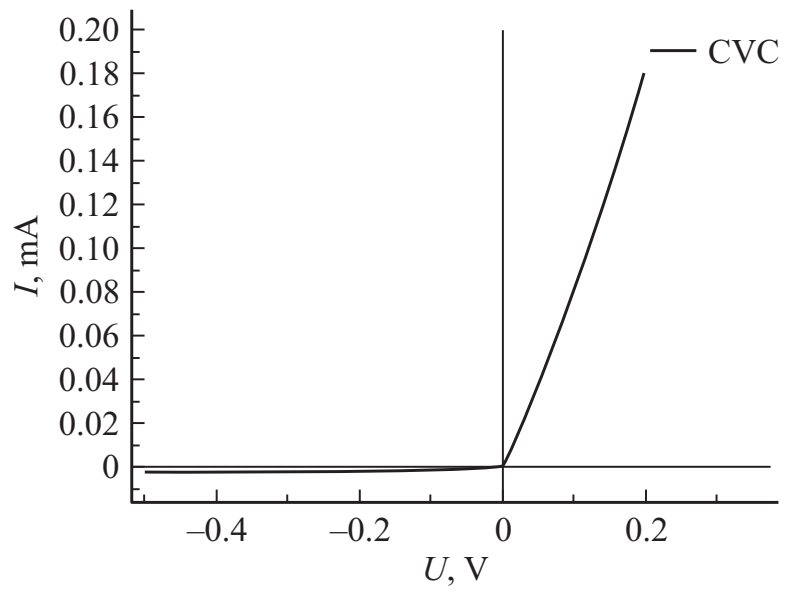

Рис. 5. Вольтамперная характеристика структуры $\mathrm{Cu} / \mathrm{Cu}_{2} \mathrm{O}$.

запрещенной зоны $E_{g}=2.11 \mathrm{eV}$ согласно формуле

$$
\lambda=h c / E_{g},
$$

где $\lambda-$ длина волны, $\mu \mathrm{m} ; ~ h-$ постоянная Планка; $c$ - скорость света; $E_{g}-$ ширина запрещенной зоны полупроводника, $\mathrm{eV}$.

Вольтамперная характеристика структуры $\mathrm{Cu}-\mathrm{Cu}_{2} \mathrm{O}$ (рис. 5), снятая с помощью четырехзондового метода [10], показывает наличие барьера Шотки как основы для создания фотопреобразователя.

\section{4. Фотоэлектрические свойства структуры $\mathrm{Cu}-\mathrm{Cu}_{2} \mathrm{O} / \mathrm{Cd}-\mathrm{Sn}-\mathrm{O}$}

После 3-5 циклов нанесения раствора и пиролиза при $450^{\circ} \mathrm{C}$ были получены прозрачные пленки, поверхностное сопротивление которых снижается с увеличением толщины пленок. Повышение мольного содержания кадмия приводит к снижению поверхностного сопротивления пленок $\mathrm{Cd}-\mathrm{Sn}-\mathrm{O}$ и при соотношении $\mathrm{Cd}-\mathrm{Sn}=4: 1$ составило $400 \Omega / \square$, a $\mathrm{Cd}-\mathrm{Sn}=6: 1$ достигает значения $200 \Omega / \square$. Дальнейшее повышение мольной доли кадмия приводило к резкому возрастанию поверхностного сопротивления (рис. 6).

Данные по фотоотклику структур $\mathrm{Cu}-\mathrm{Cu}_{2} \mathrm{O}$ и $\mathrm{Cu}-\mathrm{Cu}_{2} \mathrm{O} / \mathrm{Cd}-\mathrm{Sn}-\mathrm{O}$ были получены с использованием прямого солнечного света, интенсивность излучения которого в солнечную погоду заранее известна и для географической широты г. Красноярска составляет $835 \mathrm{~W} / \mathrm{m}^{2}$. В качестве параметра фотоотклика измеряли световой ток короткого замыкания. Эффективность фотопреобразования структуры $\mathrm{Cu}-\mathrm{Cu}_{2} \mathrm{O}$ составила $2.3 \%$. После нанесения на структуру $\mathrm{Cu}-\mathrm{Cu}_{2} \mathrm{O}$ контактного прозрачного слоя $\mathrm{Cd}-\mathrm{Sn}-\mathrm{O}$ эффективность фотопреобразования всей структуры составила 5.3\%. При этом максимальная плотность светового тока короткого замыкания $9 \mathrm{~mA} / \mathrm{cm}^{2}$, рабочая плотность светового тока короткого замыкания $7 \mathrm{~mA} / \mathrm{cm}^{2}$, плотность темнового тока короткого замыкания $0.4 \mathrm{~mA} / \mathrm{cm}^{2}$, напряжение световое $0.5 \mathrm{~B}$, напряжение темновое $0.09 \mathrm{~B}$.

Значительное увеличение эффективности фотопреобразования по сравнению с $2.3 \%$ в структуре $\mathrm{Cu}-\mathrm{Cu}_{2} \mathrm{O}$ можно объяснить следующими факторами. По нашему предположению, в результате нанесения слоя $\mathrm{Cd}-\mathrm{Sn}-\mathrm{O}$ сформировалась гетероструктура, энергетическая диаграмма которой приведена на рис. 7.

Так как солнечный элемент работает без приложения внешнего смещения, уровень Ферми является единым для всей структуры. Оксид меди $\mathrm{Cu}_{2} \mathrm{O}$ с шириной запрещенной зоны $2.12 \mathrm{eV}$ является полупроводником $p$-типа, прозрачный проводящий оксид $\mathrm{Cd}-\mathrm{Sn}-\mathrm{O}$ с шириной запрещенной зоны $\approx 3 \mathrm{eV}-$ полупроводником $n$-типа. Образуется гетеропереход с эффектом широкозонного „окна“. Свет с энергией, меньшей ширины запрещенной зоны оксида $\mathrm{Cd}-\mathrm{Sn}-\mathrm{O}$, проходит почти без поглощения в узкозонный оксид $\mathrm{Cu}_{2} \mathrm{O}$. Часть этого излучения $\mathrm{c}$ энергией, большей ширины запрещенной зоны $\mathrm{Cu}_{2} \mathrm{O}$, генерирует электронно-дырочные пары, которые разделяются полем гетероперехода. Поскольку слой $\mathrm{Cd}-\mathrm{Sn}-\mathrm{O}$ сам является фотоактивным материалом, то в нем тоже генерируются носители. Наличие высоких потенциальных барьеров на гетеропереходе и барьере Шотки не

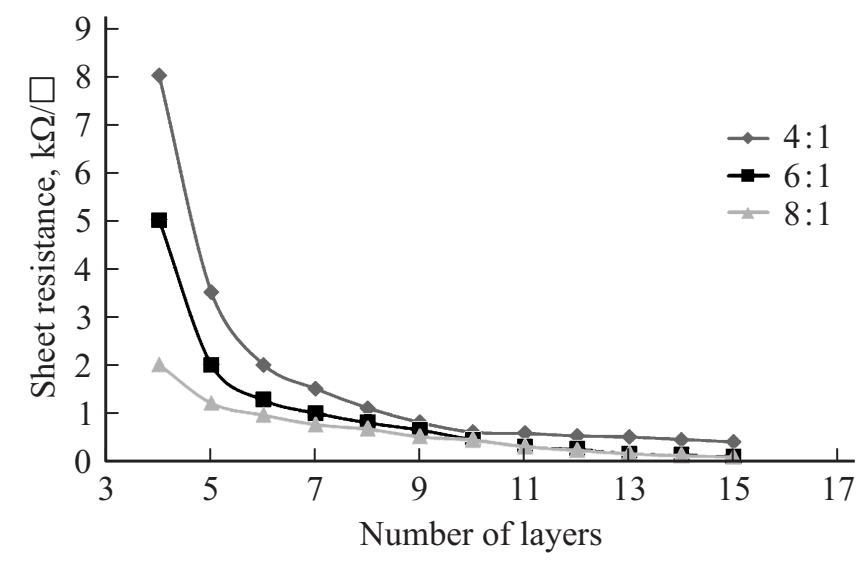

Рис. 6. Зависимость поверхностного сопротивления пленки от количества нанесенных слоев $(N)$ и от соотношения компонентов $\mathrm{Cd}: \mathrm{Sn}$.

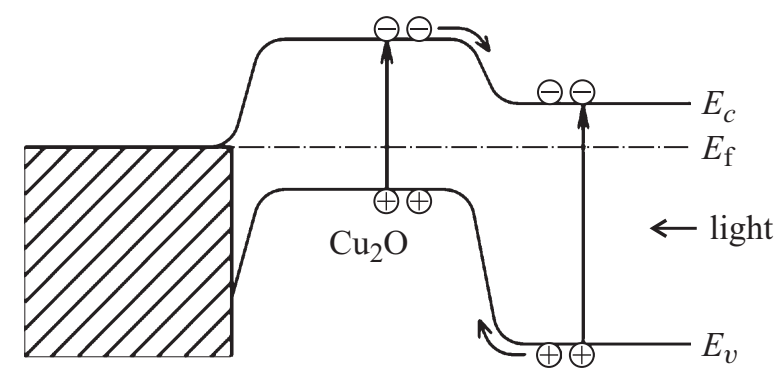

$\mathrm{Cu}$

$\mathrm{Cd}-\mathrm{Sn}-\mathrm{O}$

Рис. 7. Энергетическая диаграмма гетероструктуры $\mathrm{Cu}-\mathrm{Cu}_{2} \mathrm{O} / \mathrm{Cd}-\mathrm{Sn}-\mathrm{O}$. 
позволяет электронам из слоя $\mathrm{Cd}-\mathrm{Sn}-\mathrm{O}$ и дыркам из слоя $\mathrm{Cu}_{2} \mathrm{O}$ оттекать в соседние области. В результате слой $\mathrm{Cu}_{2} \mathrm{O}$ заряжается положительно, а слой $\mathrm{Cd}-\mathrm{Sn}-\mathrm{O}$ отрицательно. Таким образом, гетероструктура работает как солнечный элемент, для создания которого не требуется процессов диффузии, сплавления или эпитаксии, а омическими контактами являются медь и проводящий слой $\mathrm{Cd}-\mathrm{Sn}-\mathrm{O}$.

\section{5. Заключение}

Основным рыночным конкурентом солнечных элементов на основе оксида меди (I) являются коммерческие солнечные элементы на основе монокристаллического, поликристаллического, гидрогенизированного и аморфного кремния. Однако следует перечислить и существенные преимущества солнечных элементов на основе оксида $\mathrm{Cu}_{2} \mathrm{O}$ : применение распространенных материалов, не требующих высокого уровня очистки, простота получения структуры, использование стандартного недорогого оборудования, возможность эксплуатации полученных солнечных элементов в широком диапазоне температур, низкая токсичность производства и компонентов, механическая прочность и коррозионная стойкость исходной меди.

Возможность адаптации технологического процесса производства для САПР формирует потенциал для создания солнечных элементов с большой рабочей площадью поверхности различной кривизны, что значительно расширяет сферу их применения в сравнении с другими типами солнечных элементов и делает их весьма привлекательными для широкого использования в коммерческих целях.

Анализируя литературные и экспериментальные данные, можно констатировать, что гетероструктура $\mathrm{Cu}-\mathrm{Cu}_{2} \mathrm{O} / \mathrm{Cd}-\mathrm{Sn}-\mathrm{O}$, полученная методами малозатратной технологии из недорогого сырья, может стать основой для создания солнечных батарей в интересах малой энергетики.

Авторы признательны А.Я. Корецу за проведение оптических измерений и Г.А. Бондаренко за рентгенографические исследования.

\section{Список литературы}

[1] L. Castañeda, D.S. Ginley, C. Bright. Mater. Sci. Appl. MRS Bull. 2, 1233 (2011).

[2] А.И. Холькин, Т.Н. Патрушева. Экстракционно-пиролитический метод получения оксидных функциональных материалов. КомКнига, М. (2006). 276 с.

[3] Т.Н. Адрианова, А.А. Захаров, Е.А. Миронов, С.Н. Слюньков. В сб.: Докл. конф. КГТУ. УЛьтрадисп. порошки и материалы. (1999). С. 134.

[4] Л.П. Павлов. Методы определения основных параметров полупроводниковых материалов. Высш. шк. М., (1990). $206 \mathrm{c}$.
[5] Л.А. Светличная. В сб.: Электрохимия. Таганрогский технологический институт Южного федерального ун-та 45, 7, 858 (2009).

[6] A.H. Jayatissa, K. Guo, A.C. Jayasuriya. Appl. Surf. Sci. 23, 255, 9474 (2009).

[7] T.D. Golden, M.G. Shumsky, Y. Zhou. Chem. Mater. 8, 10. 2499 (1996).

[8] M.T. Nair, L. Guerrero. Appl. Surf. Sci. 150, 1-4, 143 (1999).

[9] E. Fortin, D. Masson. Solid-State Electron. 25, 4. 281 (1982); G.T.D. Olden, M.G. Shumsky, Y. Zhou. Chem. Mater. 8, 10, 2499 (1996).

[10] В. Дьяконов. Компоненты и технологии 10, 137 (2010). 